\title{
Tipología con fines pedagógicos de los verbos locativos del español
}

\author{
A typology of locative verbs in Spanish for pedagogical purposes
}

Roana RODRIGUES*

\begin{tabular}{|c|c|}
\hline $\begin{array}{l}\text { RESUMEN: Las construcciones verbales } \\
\text { locativas son las que establecen una } \\
\text { relación de ubicación entre los elementos } \\
\text { en el interior de una frase simple. En este } \\
\text { artículo, se describe el funcionamiento } \\
\text { sintáctico-semántico de las construcciones } \\
\text { locativas de la lengua española, en que el } \\
\text { elemento locativo no es un simple } \\
\text { complemento circunstancial, sino hace } \\
\text { parte de la valencia del verbo (argumental } \\
\text { locativo). Partiéndose de la clasificación de } \\
\text { 318 construcciones verbales locativas del } \\
\text { español, se propone una nueva tipología } \\
\text { verbal, la cual considera el contexto de } \\
\text { enseñanza y aprendizaje del fenómeno. } \\
\text { Las 318 construcciones fueron } \\
\text { redistribuidas en dos grandes clases } \\
\text { formales: verbos locativos preposicionales } \\
\text { (VLP) y verbos locativos transitivos } \\
\text { directos (VLTD). Además, basado en sus } \\
\text { principales propiedades semánticas, se } \\
\text { estableció la siguiente organización } \\
\text { categórica de verbos: prototípicos, } \\
\text { restrictivos y denominales -y la mención a las } \\
\text { construcciones fóricas. Los términos fueron } \\
\text { creados en esta investigación, teniendo } \\
\text { como principal objetivo la sistematización } \\
\text { de los datos con propósitos pedagógicos, } \\
\text { para la enseñanza del español comolengua } \\
\text { materna y/o lengua extranjera. Las } \\
\text { discusiones y tipologías propuestas }\end{array}$ & $\begin{array}{l}\text { ABSTRACT: In locative verbal } \\
\text { constructions, there is always a relation of } \\
\text { localization between elements within the } \\
\text { same sentence. In this article, we describe } \\
\text { the syntactic-semantic behavior of the } \\
\text { locative constructions in Spanish, in } \\
\text { which the locative element is not just a } \\
\text { complement but is part of the valency of } \\
\text { the verb (argumental locativo). Starting } \\
\text { from the classification of } 318 \text { locative } \\
\text { verbal constructions in Spanish, a new } \\
\text { typology is proposed, considering the } \\
\text { teaching and learning context in which it } \\
\text { can be applied. The } 318 \text { constructions } \\
\text { were redistributed into two formal } \\
\text { classes: prepositioned locative verbs and } \\
\text { direct transitive locative verbs. In } \\
\text { addition, based on their main semantic } \\
\text { properties, we presented the following } \\
\text { classes of verbs: prototypic, restrictive and } \\
\text { denominational, as well as mentions to the } \\
\text { phoric constructions. The terms were } \\
\text { created in this paper, being the main } \\
\text { objective a systematization of data for } \\
\text { pedagogical purposes, having in } \\
\text { perspective the teaching of Spanish as } \\
\text { first and/or foreign language. The } \\
\text { proposed discussions and typology } \\
\text { contribute to the identification of the role } \\
\text { of these constructions in the descriptive } \\
\text { studies of natural languages. }\end{array}$ \\
\hline
\end{tabular}

Doutora em Linguística. Professora da UFS. ORCID: https://orcid.org/0000-0002-7748-8716. r.roanarodrigues@gmail.com. 
contribuyen con la identificación del papel de esas construcciones en los estudios descriptivos de las lenguas naturales.

PALABRAS CLAVE: Construcciones locativas. Verbos locativos del español. KEYWORDS: Locative constructions. Propuesta de tipología. Locative verbs in Spanish. Typology proposal.

\section{Introducción ${ }^{1}$}

Las construcciones verbales locativas son las que establecen una relación de ubicación entre los elementos en el interior de una frase (oración) simple. Desde una perspectiva formal del fenómeno, el locativo (o lugar) puede hacer parte de la valencia verbal, como en la frase (1), o ser un complemento circunstancial, como en la (2) ${ }^{2}$ :

(1) Las Vegas instaló cámaras en los pasillos.

(2) La madre le contó la historia a la policía en el pasillo.

En (1), el verbo instalar selecciona tanto un complemento directo (cámaras) como un argumento preposicional interpretado como lugar de destino (en el pasillo). En la frase (2), el verbo contar selecciona como argumentos esenciales un elemento en la posición de complemento directo (la historia) y uno en la posición de complemento indirecto (a la policía), así el locativo se clasifica como un complemento circunstancial (en el pasillo). Las gramáticas de lengua española presentan esa diferencia cuando afirman, de manera general, que en (1) el locativo es un argumento del verbo, que en este trabajo nombramos argumento locativo; y en (2), el locativo es un complemento circunstancial, al cual nos referimos como adjunto cénico ${ }^{3}$.

\footnotetext{
${ }^{1}$ Los datos presentados en este artículo son resultado de la tesis doctoral de Rodrigues (2019).

${ }^{2}$ Las frases que aparecen en este artículo fueron adaptadas de la web, con la ayuda de la herramienta WebCorp, disponible en: http://www.webcorp.org.uk/live/. Acceso: entre dic. 2018 y jun. 2019.

${ }^{3}$ El término cénico se basa en los trabajos léxico-gramaticales de Macedo (1987), sobre el portugués europeo, y Guillet y Leclère (1992), sobre el francés.
} 
El fenómeno de las construcciones verbales locativas ha sido tema de estudios lingüísticos sobre diversas lenguas naturales, a partir de diferentes bases teóricometodológicas, como, por ejemplo, los trabajos precursores de Macedo (1987), sobre el portugués europeo, Rojas Nieto (1988) sobre el español, y Guillet y Leclère (1992) sobre el francés. ${ }^{4}$

Las gramáticas de lengua española también parecen preocuparse con el lugar ocupado por esas construcciones en los estudios descriptivos (y prescriptivos) de la lengua. Campos (1999), en la Gramática descriptiva de la lengua española, ejemplifica el argumental locativo a partir de la predicación del verbo poner, la cual reproducimos abajo:

(3) a. Pablo puso los pollos en el corral.

b. *Pablo puso en el corral.

c. *Pablo puso los pollos.

d. *Pablo puso.

Se verifica que el verbo poner selecciona tanto un argumento en la posición de complemento directo (los pollos), como un argumental locativo, introducido por preposición (en el corral), "que parece circunstancial" (CAMPOS, 1999, p. 1522). Como se trata de un elemento seleccionado por el verbo, haciendo parte de su valencia, lo clasificamos como argumental y enfatizamos su importancia en la constitución de la frase de base.

Asimismo, el Manual de la Nueva gramática de la lengua española (ESPAÑOLA; ESPAÑOLA, 2010) presenta el carácter especial de los locativos verbales, que no actúan como complementos circunstanciales, tampoco deben ser confundidos con

4 Los estudios descriptivos (GUILLET; LECLÈRE, 1992; GARCÍA-MIGUEL, 2006; CORRÊA; CANÇADO, 2006; MIOTO et al., 2007; BAPTISTA, 2013; RODRIGUES, 2016) proponen una serie de testes formales para la identificación del argumental locativo, alejándolo de la función de complemento circunstancial. Para la construcción del Léxico-Gramática de los verbos Locativos del Español (LGLE), nos basamos en 9 testes formales, que pueden ser consultados en Rodrigues (2019). 
complementos de régimen ${ }^{5}$. En esa gramática, se describen los locativos del verbo como argumentales de ubicación, como se verifica en la frase (4), en que el operador (poner) selecciona argumentos para completar su predicación, que pueden ser introducidos por diferentes preposiciones:

(4) Puso el libro (en + sobre + bajo + tras + ante) la mesa.

De acuerdo con el Manual,

Los complementos argumentales de ubicación, seleccionados por poner, guardar, ocultar, situar y otros verbos similares, pueden construirse también con adverbios y locuciones prepositivas, como al lado (de), cerca (de), debajo (de), encima (de), frente a, junto a, etc., y pueden ser sustituidos por los adverbios allí, allá, dónde o donde. El límite entre los complementos de régimen y los circunstanciales tampoco es nítido con los verbos caber, pernoctar o residir, que presentan mayor necesidad de un complemento locativo que otros como apoyarse, tenderse o veranear. (ESPAÑOLA; ESPAÑOLA, 2010, p. 687).

Se percibe una preocupación en la tradición gramatical de lengua española con el papel desempeñado por los argumentales locativos. Sin embargo, como se nota en la cita, no se tienen muy "nítidos" los límites y las particularidades de esas construcciones.

Con el propósito de contribuir con los estudios descriptivos de las lenguas naturales, en especial de la lengua española, proponemos, en este trabajo, una tipología didáctica de las construcciones verbales locativas. Para eso, nos orientamos, fundamentalmente, en las contribuciones de las bases de datos verbales ADESSE (GARCÍA-MIGUEL et al., 2003) y ViPEr (BAPTISTA, 2013), que presentan una

\footnotetext{
${ }^{5}$ Los complementos circunstanciales (o adjuntos) no hacen parte de la valencia verbal, es decir, no son seleccionados por el verbo. Los complementos de régimen son argumentales que hacen parte de la valencia verbal y se introducen por preposiciones determinadas y específicas, motivadas por factores históricos y semánticos (confiar en, disfrutar de, recurrir a, etc.).
} 
descripción minuciosa sobre los verbos de espacio / locativos de la lengua española y de la lengua portuguesa, respectivamente.

En la Sección 2, presentaremos los procedimientos metodológicos para el establecimiento de la lista de construcciones verbales locativas que componen el Léxico-Gramática ${ }^{6}$ de los verbos Locativos del Español (LGLE), base de datos que nos sirvió de soporte para la propuesta de tipología, descripta en la Sección 3, que defendemos en esta investigación. En las consideraciones finales, sintetizamos las contribuciones de este trabajo.

\section{La construcción del LGLE}

El LGLE (Léxico-Gramática de los verbos Locativos del Español) es una base de datos que agrupa 318 construcciones verbales locativas del español organizadas en 10 clases distintas, a depender de sus propiedades estructurales (número de argumentos, preposiciones); distribucionales (nombre humano / no humano, locativo de origen / de trayectoria / de destino) y transformacionales (operación de fusión y construcciones pasivas). Para su creación, analizamos y contrastamos dos bases de datos verbales que presentan la descripción del fenómeno locativo: ADESSE, del español, y ViPEr, del portugués europeo. Además, nos basamos en frases adaptadas de la web, sacadas de sitios de la variante escrita culta del español peninsular, y validadas por informantes hispanohablantes nativos.

ADESSE (GARCÍA-MIGUEL et al., 2003) es un proyecto desarrollado en la Universidad de Vigo (Galicia, España), que presenta las propiedades sintácticosemánticas de los verbos del español, con una propuesta de clasificación inspirada en

\footnotetext{
${ }^{6}$ El Léxico-Gramática (GROSS, 1975) es un modelo teórico-metodológico que propone una descripción minuciosa, introspectiva y exhaustiva de los fenómenos lingüísticos de las lenguas naturales. Rompiéndose con la tradicional noción de sujeto y predicado (BATISTA, 2008), se considera que cada ítem lexical (en este caso, el verbo locativo) tiene una gramática propia. Los datos son distribuidos en tablas binarias, en que las líneas presentan el objeto nuclear analizado y las columnas, sus propiedades estructurales, distribucionales y transformacionales.
} 
las clases semánticas de Levin (1993). Se trata de una base de datos disponible de manera gratuita en la $w e b^{7}$, con la descripción de más de 4.000 construcciones verbales distribuidas por 6 macroclases (Mental, Relacional, Material, Verbal, Existencial, Modulación) y 20 subclases. La subclase de nuestro interés, Espacio, se encuentra en la macroclase Material y está subdividida en: Espacio (5), Desplazamiento (230), Localización (219), Postura-Posición (42), Orientación (10), Manera Movimiento (43) y Unión (125)ㄹ, lo que totaliza 674 construcciones verbales espaciales.

ViPEr (BAPTISTA, 2013) es una base de datos verbales del portugués europeo, a la cual ya se han sumado algunos verbos más usuales o específicos del portugués brasileño (RODRIGUES, 2016). Se trata de un proyecto en desarrollo, cuyos datos utilizados en esta investigación se basan en su versión 158, disponibles directamente por el investigador responsable por el proyecto. Tiene como base teórico-metodológico el modelo del Léxico-Gramática y presenta la descripción sistemática de las propiedades estructurales, transformacionales y distribucionales de aproximadamente 7.000 construcciones verbales distribuidas por 71 clases, de entre las cuales $12^{9}$ son clasificadas como locativas, con el análisis y clasificación de 1.142 verbos de lugar.

Destacamos que utilizamos ViPEr como nuestra base de datos de referencia porque compartimos la mayoría de sus testes formales para la identificación del argumental locativo y la misma base teórico-metodológica, el modelo del LéxicoGramática. Además, se trata de una base verbal que agrupa un mayor número de

\footnotetext{
${ }^{7}$ Base de datos ADESSE. Disponible en: http://adesse.uvigo.es/data/clases.php. Último acceso: jun. 2019. ${ }^{8}$ El número entre paréntesis representa la cantidad de verbos descriptos en cada clase.

${ }^{9}$ Las clases verbales locativas de ViPEr son las siguientes: 35LS (No V-stat Loc1 Nloc1); 35LD (No V-din Loc1 Nloc1); 37LD (No V-din Loc-s1 Nloc1 Loc-d Nloc $_{2}$ ); 38L1 (No V Nloc1); 38L2 (No Nloc-v Nobj1 [V=poner en Nloc]); 38L3 (Nloco V Nobj1); 38L4 (No Nobj-v Nloc-d1 [V=poner Nobj]); 38L5 (No Nobj-v Nloc-s1 [V=quitar de

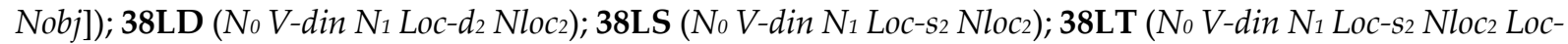
$\left.d_{3} N l o c_{3}\right) ; y 38 R$ ( $N_{0} V$-stat $N_{1} L_{o c} N_{2}$ ). Entre paréntesis está la representación estructural de cada clase, en que: $N_{0}, N_{1}, N_{2}$ : sujeto y complementos; Nloc: nombre locativo; Nloc-v: verbo denominal de lugar; Nobj-v: verbo denominal de objeto; Loc: preposición locativa, $-d$ de destino, $-s$ de origen; $V$ : verbo, $V$-din: verbo locativo dinámico; $V$-stat: verbo locativo estático.
} 
construcciones y se reconoce como más granular $^{10}$. Con el intento de ejemplificar tal granularidad, presentamos las construcciones con el verbo habitar:

(5) a. El pescado habita las aguas del cono sur americano. [Localización]

O peixe habita as águas do cone sul-americano.

b. El crustáceo habita en refugios rocosos.

O crustáceo habita em abrigos rochosos.

En ADESSE, el verbo habitar sólo posee una entrada en la clase Localización. Sin embargo, en ViPEr, debido a la diferencia sintáctica, se duplica el verbo, agrupándolo en las clases: 38L1, en que el locativo ocupa la posición de complemento directo; y 35LS, de construcciones locativas estáticas, cuyo locativo es introducido por la preposición en.

Respetando las particularidades teórico-metodológicas de ADESSE y ViPEr, realizamos, de manera manual, un análisis comparado entre los verbos locativos de las dos bases de datos, estableciendo así la lista de candidatos a construcciones verbales locativas del español, los cuales tuvieron sus propiedades estructurales, transformacionales y distribucionales debidamente analizadas, generando el LGLE (Léxico-Gramática de los verbos Locativos del Español), como se verifica en la Tabla 1 a continuación:

\footnotetext{
${ }^{10}$ Cuando adjetivamos una base de datos como granular queremos decir que se trata de un trabajo en que los datos son más desmenuzados, en un intento de presentar los pequeños cambios sintácticosemánticos de las construcciones analizadas.
} 
Tabla 1 - LGLE: Léxico-Gramática de los verbos Locativos del Español.

\begin{tabular}{|c|c|c|c|}
\hline Clase & Estructura $^{11}$ & Ejemplo & \# \\
\hline 35LD & $\mathrm{N}_{0}$ Vdin $\mathrm{Loc}_{1} \mathrm{Nloc}_{1}$ & Los migrantes accedieron a costas españolas. & 66 \\
\hline $35 \mathrm{LS}$ & $\mathrm{N}_{0}$ Vstat Loc $\mathrm{Nloc}_{1}$ & Una obra reposó en los almacenes de la pinacoteca. & 15 \\
\hline 37LD & $\mathrm{N}_{0}$ Vdin Loc-s Nloc $_{1}$ Loc-d $_{2}$ Nloc $_{2}$ & El hombre saltó desde la plataforma hasta la pista. & 46 \\
\hline $38 \mathrm{~L} 1$ & $\mathrm{~N}_{0} \mathrm{~V} \mathrm{Nloc}{ }_{1}$ & El jugador abandonó el recinto. & 43 \\
\hline 38L2 & $\mathrm{N}_{0}$ Nloc-v [prep-a] $\mathrm{N}_{1}[\mathrm{~V}=$ poner en Nloc $]$ & El actor empaquetó sus cosas. & 7 \\
\hline $38 \mathrm{~L} 3$ & $\mathrm{Nloc}_{0} \mathrm{~V}$ [prep-a] $\mathrm{N}_{1}$ & El pequeño hotel albergaba a un grupo. & 4 \\
\hline 38LD & $\mathrm{N}_{0}$ Vdin [prep-a] $\mathrm{N}_{1}$ Loc-d $_{2} \mathrm{Nloc}_{2}$ & El estudiante guardó el libro en el estante. & 101 \\
\hline 38LS & $\mathrm{N}_{0}$ Vdin [prep-a] $\mathrm{N}_{1}$ Loc-s $_{2} \mathrm{Nloc}_{2}$ & La policía evacuó a los turistas del lugar. & 19 \\
\hline 38LT & $\begin{array}{r}\mathrm{N}_{0} \text { Vdin [prep-a] N } \text { Loc-S }_{2} \text { Nloc }_{2} \text { Loc-d }_{3} \\
\mathrm{Nloc}_{3}\end{array}$ & Isabel Il canalizó el agua del Lozoya hasta Madrid. & 14 \\
\hline $38 \mathrm{R}$ & $\mathrm{N}_{0}$ Vstat [prep-a] $\mathrm{N}_{1}$ Loc $_{2} \mathrm{~N}_{2}$ & Eduardo localizó el poblado minero en el mapa. & 3 \\
\hline & & $\begin{array}{ll} & \text { Total }\end{array}$ & 318 \\
\hline
\end{tabular}

Fuente: Rodrigues (2019, p. 123).

En la Tabla 1, presentamos las 10 clases de construcciones verbales locativas del LGLE. La clasificación sigue los patrones presentados en investigaciones léxicogramaticales anteriores: las construcciones transitivas locativas del francés (GUILLET; LECLÈRE, 1992) y los verbos locativos de ViPEr (BAPTISTA, 2013). Aunque la clasificación mantenga los principios del modelo del Léxico-Gramática y, por lo tanto, facilite el análisis y la comparación de los datos entre las lenguas naturales, se percibe que la nomenclatura, en que las clases se identifican por medio de "códigos", se aleja de la terminología empleada en sala de clase. Por eso, con la intención de aproximar la descripción lingüística a la enseñanza del fenómeno, propusimos en este trabajo una nueva tipología, la cual pone énfasis en las principales características de las construcciones locativas de la lengua española.

\footnotetext{
11 Notaciones: $N_{0}, N_{1}, N_{2}$ : sujeto y complementos; Prep: preposición; [prep-a]: posibilidad de la preposición $a$ cuando $\mathrm{N}_{1}$ es un nombre humano; Nloc: nombre locativo; Loc: preposición locativa; -d de destino, -s de origen; V: verbo, Vdin: verbo locativo dinámico; Vstat: verbo locativo estático.
} 


\section{Verbos locativos del español: clasificación con fines pedagógicos}

La tipología propuesta en este trabajo pretende contribuir con la enseñanza del español como lengua materna o extranjera. ${ }^{12}$ La nueva clasificación consistió en organizar los 318 verbos locativos del español en dos grandes clases, según su estructura formal: verbos locativos preposicionales (VLP) y verbos locativos transitivos directos (VLTD), como se presenta en las frases (6) y (7), respectivamente:

(6) a. El cadáver de Picasso yace en Málaga.

b. Juan envió una delegación a Brasil.

c. El Ministerio excluyó a las islas Malvinas del mapa argentino. [VLP]

d. Cipriano merodeó por las cercanías del barrio chino.

(7) a. La caja contiene las joyas.

b. El conde pobló la villa.

Las frases en (6) presentan construcciones locativas en que el argumental locativo es introducido por una preposición (en, $a$, de, por). Ya en (7), el locativo figura en una construcción transitiva directa y puede ocupar la posición de sujeto, (7a), complemento directo, $(7 \mathrm{~b})$, o hacer parte de la constitución verbal en una construcción denominal, $(7 \mathrm{c})$.

Además de esas consideraciones formales sobre las construcciones verbales locativas, nos parece importante mencionar algunos rasgos semánticos generales, como organizamos en la Tabla $2 .{ }^{13}$

\footnotetext{
${ }^{12}$ Aunque el énfasis de este trabajo sea la enseñanza de la lengua española, creemos que la propuesta de tipología puede también ser aplicada a otras lenguas naturales, como el portugués y el francés.

${ }^{13}$ Las propiedades destacadas se basan en la observación de los fenómenos más frecuentes que fueron encontrados en el LGLE.
} 
Tabla 2 - Propiedades de las clases locativas VLP y VLTD.

\begin{tabular}{|c|c|c|}
\hline Clase & Definición & Ejemplo \\
\hline Prototípico & $\begin{array}{l}\text { general } \\
\text { Nloc = ocupado por varios argumentos posibles. }\end{array}$ & $\begin{array}{r}\text { Robert entró en (la sinagoga + la } \\
\text { ciudad+ el hospital). }\end{array}$ \\
\hline \multirow{2}{*}{ Restrictivo } & $\begin{array}{l}\text { por omisión } \\
\text { Nloc = posibilidad de omisión. }\end{array}$ & $\begin{array}{r}\text { El dueño subió las valijas [del segundo] } \\
\text { hasta el tercer piso. }\end{array}$ \\
\hline & $\begin{array}{l}\text { por toponimia } \\
\text { Nloc = ocupado por un nombre toponímico. }\end{array}$ & Wintour aterrizó en Nueva York. \\
\hline \multirow{3}{*}{ Denominal } & $\begin{array}{l}\text { de lugar } \\
\mathrm{V}_{\text {lugar }}=\text { verbo constituido por un nombre de lugar. }\end{array}$ & El artista enmarcó el cuadro. \\
\hline & $\begin{array}{l}\text { de instrumento } \\
\mathrm{V}_{\text {instrumento }}=\text { verbo constituido por un nombre de } \\
\text { instrumento <con + instrumento }>\text {. }\end{array}$ & Lena encadenó al perro en el patio. \\
\hline & $\begin{array}{l}\text { de manera-posición } \\
V_{\text {Maneraposición }}=\text { verbo constituido por un nombre que } \\
\text { establece una relación comparativa: } \\
\text { <de la manera de | como + objeto }>\end{array}$ & La tormenta circuló hacia el norte. \\
\hline Fórico & Considera la enunciación. & Pablo vino de Brasil. \\
\hline
\end{tabular}

Fuente: Rodrigues (2019, p. 134).

A continuación, describiremos las particularidades de cada una de las propiedades dispuestas en la Tabla 2.

Iniciando con los verbos locativos prototípicos, están las construcciones que seleccionan los argumentos para completar su predicación, sin presentar grandes restricciones a los nombres que ocupan las posiciones de sujeto y complementos (salvo la diferenciación entre nombre humano y no humano). Se trata de construcciones más generales y recurrentes de la lengua española, pudiendo presentar diferentes composiciones sintáctico-semánticas.

Diferente de los verbos prototípicos, los verbos restrictivos presentan alguna exigencia semántica para completar su valencia. En este trabajo, apuntamos dos tipos de restricciones: (i) la omisión de un argumento locativo, y (ii) la selección de un nombre toponímico en la posición de argumento locativo.

Algunos verbos seleccionan un argumento de origen y también un argumento de destino como elementos esenciales de su valencia. De acuerdo con la clasificación del LGLE, se tratan de los verbos de las clases 37LD, como en la frase (8), y 38LT, como en la (9), que se diferencian por el elemento desplazado (sujeto y complemento directo, respectivamente): 
(8) El hombre partió desde San Pedro Sula rumbo a los Estados Unidos.

(9) El dueño mudó el equipo de la Ciudad de México a Aguascalientes.

Algunas construcciones permiten la supresión de uno de sus locativos (de origen o de destino), sin que haya problemas en la interpretación del significado de la frase de base. Según Cavalcante (1997, p. 13), “aunque la omisión sea un fenómeno del discurso, determinada por condicionadores pragmático-discursivos, los parámetros semántico-sintácticos posibilitan diferentes grados de omisión facultativa"14. De ese modo, de acuerdo con los análisis sintáctico-semánticos, algunas construcciones locativas del LGLE (aproximadamente 20) permiten la omisión del elemento de lugar de origen o de destino, como ejemplificamos a partir del análisis de los verbos salir (37LD) y transportar (38LT):

(10)a. Madonna salió de Michigan hacia Nueva York.

b. Madonna salió de Michigan.

c. ¿? Madonna salió hacia Nueva York. ${ }^{15}$

(11) a. Thomas transportó millones de pasajeros de la capital hasta el archipiélago.

b. ¿? Thomas transportó millones de pasajeros de la capital.

c. Thomas transportó millones de pasajeros hasta el archipiélago.

En (10a), el verbo salir selecciona tanto un lugar de origen (de Michigan), como uno de destino (hacia Nueva York). Cuando es omitido el lugar de destino, (10b), la frase sigue aceptable, sin daños de comprensión. Sin embargo, la omisión del lugar de origen, sin la seguridad de que se puede retomarlo contextualmente, causa dudas sobre la aceptabilidad de la frase, (10c).

14 Traducción libre de: "a omissão é um fenômeno do discurso, que, sendo determinada por condicionadores pragmático-discursivos, é, no entanto, possibilitada por parâmetros semânticosintáticos responsáveis pelos diferentes graus de facultatividade." (CAVALCANTE, 1997, p. 13).

${ }^{15}$ Las interrogaciones marcan la aceptabilidad dudosa de la frase. 
Con el verbo transportar, (11a), la relación es contraria, es decir, el elemento fundamental es el de destino, (11c), que necesita estar expresado en la frase; ya el argumento de origen, (11b), puede ser omitido.

La segunda restricción apuntada en esta investigación es la toponímica. Los topónimos son los nombres propios que indican un lugar y suelen ser los que mejor se encajan con la función de argumental locativo:

(12) a. La Policía deportó a Mateos a España.

En el LGLE encontramos 16 construcciones verbales que seleccionan un argumental locativo ocupado por un nombre toponímico: asilar, aterrizar, atracar, despoblar, emigrar, viajar, zarpar, etc. Además del nombre propio en sí, el argumento puede ser ocupado por su hiperónimo (ciudad, montaña, país, etc.):

(12) b. La Policía deportó a Mateos a su país de origen.

Los verbos denominales, a su vez, se constituyen por una base nominal (estacionar: estacionamiento, centralizar: centro, empantanar: pantano). En el caso de las construcciones locativas, los estudios lingüísticos suelen discutir sobre los verbos locativos y locatum. Según Matera y Medina (2005, p. 4), la frase (13) ejemplifica el caso de construcciones locativas, en que el verbo se constituye por un nombre cognado de lugar (enjaular: en la jaula); ya la frase (14) demuestra una construcción locatum, en la cual el verbo tiene como base un nombre cognado de objeto (ensillar: la silla).

(13) a. Juan enjauló el pájaro.

(14) a. El peón ensilló el caballo.

Según los autores, basados en los presupuestos de la Gramática Generativa, las construcciones locativas se relacionan con la estructura del verbo (locativo) poner, (13b). 
Ya las construcciones locatum establecerían una relación con el verbo (no locativo) proveer, (14b), alejándose así de las construcciones comúnmente identificadas como locativas:

(13) b. Juan puso el pájaro en la jaula.

(14) b. El peón proveyó al caballo con una silla. ${ }^{16}$

En ViPEr, se analizan las construcciones locatum como locativas de las clases 38L4 y 38L5 ${ }^{17}$. Sin embargo, ante la dificultad de interpretación locativa de los elementos que ocupan la posición de complemento directo (¿caballo sería un lugar?), elegimos descartar esas construcciones, analizand y y clasificando solamente los verbos de base nominal locativos.

Para la identificación de los verbos denominales locativos, aplicamos la operación de fusión (GROSS, 1981), como propone Baptista (2013, p. 123) en ViPEr, que consiste en la construcción de una paráfrasis con el operador poner y un predicado locativo:

(15) El gobierno encarceló a los opositores.

El gobierno puso \# los opositores están en la cárcel.

El gobierno puso \# los opositores en la cárcel.

A partir de la aplicación de la operación de fusión es posible establecer una relación locativa con la siguiente construcción: poner $\mathrm{X}$ en $\mathrm{Y}$, en que $\mathrm{X}$ es el nombre que

\footnotetext{
${ }^{16}$ Para Matera y Medina (2005, p. 9) las construcciones locativas denotan un cambio de localización del nombre que ocupa la posición de complemento directo (pájaro), cuyo papel temático es el de tema. En las construcciones locatum, el nombre que ocupa la posición de complemento directo (caballo), que tiene papel temático de paciente, es afectado por un cambio que no implica necesariamente un movimiento (el caballo está ensillado), alejándose así de una interpretación locativa. Cançado et al. (2013), sobre el portugués de Brasil, clasifican las construcciones locatum como no locativas que indican posesión.

${ }^{17}$ Así como Baptista (2013), Cifuentes Honrubia (2005, p. 337) considera las construcciones locatum como locativas, pues en una oración como Juan engrasa la puerta, la posesión (puerta engrasada) sólo se establece como un resultado de la acción locativa inicial (poner grasa en la puerta).
} 
ocupa la posición de complemento directo (a los opositores) y $Y$ es el nombre cognado de la base verbal (en la cárcel). Analizamos y clasificamos 7 construcciones verbales denominales locativas que admiten la operación de fusión en la clase 38L2 (empaquetar, encajonar, encarcelar, encuadrar, enfundar, enjaular y enmarcar).

Cabe mencionar la existencia de algunas construcciones, como almacenar, alojar, aparcar, desenterrar, que parecen haberse alejado de su sentido "original", no más permitiendo la operación de fusión, pues ahora seleccionan otro elemento interpretado como locativo en la posición de argumento preposicional:

(16) El padre estacionó el coche en la calle (en el estacionamiento de José).

Encontramos otras construcciones más en el LGLE que se constituyen por verbos denominales, aunque no permitan la operación de fusión. Al todo, apuntamos aproximadamente 45 verbos denominales, esparcidos por 8 clases distintas, de acuerdo con sus propiedades sintáctico-semánticas.

(17) a. El atracador se atrincheró tras unos setos.

b. Los hoteles atornillaron sus aparatos de televisión a la pared.

c. Un aguacero empantanó el suelo.

De este modo, además del denominal locativo, agrupamos en la clase de verbos denominales los casos en que el verbo se constituye por: (i) un nombre de lugar, admitiendo otro argumento locativo, como en (16) y en (17a); (ii) un nombre de instrumento, (17b); y un nombre que establece una relación de manera-posición, (17c).

En (17a) el verbo atrincherar selecciona un argumento interpretado como locativo de destino (tras unos setos), alejándose de la limitación que podría existir por imposición del nombre cognado que lo constituye (atrincherar en una trinchera). La frase (17b), con el verbo atornillar, ejemplifica los casos de derivación de nombres aquí interpretados como instrumento, en que se puede establecer una relación de paráfrasis: 
con <instrumento> I con tornillos. Finalmente, en (17c), el cognado manera-posición es la nomenclatura encontrada para evidenciar la construcción de la paráfrasis con la conjunción comparativa como <objeto $>$ o a la manera de <objeto $>$ | como pantano.

Aunque presenten propiedades particulares que los agrupen en clases distintas, tales construcciones comparten el polo positivo [+denominal], por eso las identificamos como una construcción específica de la lengua que merece determinado destaque en los estudios descriptivos.

Por fin, mencionamos la existencia de los verbos locativos fóricos. Según Neves (2000, p. 257), los adverbios fóricos (aquí, ahí, allá) son aquellos que hacen referencia al aquí y al ahora de la situación comunicativa y a la localización relativa del locutor, del interlocutor y del objeto sobre el cual se habla. Al analizar detenidamente los verbos locativos del LGLE, fue posible establecer una relación entre dos construcciones verbales y los adverbios fóricos. Se hizo la notación de dos verbos que, así como los adverbios fóricos, consideran la situación comunicativa, es decir, la enunciación, por eso los nombramos verbos fóricos:

(18) Pablo vino de Brasil.

(19) Carmen trajo al bebé de Rusia.

Las construcciones con venir y traer consideran el lugar ocupado por quien habla para la identificación del lugar de destino al cual determinado elemento se desplaza: alguien vino de Brasil (hacia el lugar ocupado por el hablante); alguien trajo algo de Rusia (hacia el lugar ocupado por el hablante) ${ }^{18}$.

Nos referimos a los verbos fóricos simplemente en carácter de mención, justamente porque esa relación establecida con el momento de la enunciación se torna

\footnotetext{
${ }^{18}$ Nos parece que, en determinados contextos, los verbos ir y llevar también cargan la noción de "lugar ocupado por quien habla": alguien va (del lugar ocupado por el hablante) hacia otro lugar y alguien lleva algo (del lugar ocupado por el hablante) hacia otro lugar. Sin embargo, como pueden presentarse en construcciones sin considerar la situación comunicativa, optamos por no definirlos como fóricos.
} 
evidente en sólo dos construcciones verbales analizadas (venir y traer). Se trata de un fenómeno muy particular y reducido, lo que no nos parece configurar una clase verbal. Además, se pueden asociar esas construcciones a los verbos restrictivos de omisión, pues tanto venir como traer omiten el lugar de destino, ya que coincide con el lugar ocupado por quien habla.

La nueva organización de las variadas composiciones sintáctico-semánticas de los verbos locativos del español resultó en una tipología que consiste en 2 clases formales generales (VLP y VLTD). En la Tabla 3 establecemos las relaciones entre la nueva tipología con fines didácticos y las 10 clases verbales locativas del LGLE.

\begin{tabular}{c} 
Tabla 3 - Relaciones entre Tipología Didáctica y las clases del LGLE. \\
\begin{tabular}{c|c} 
Tipología Didáctica & Clases del LGLE \\
\hline $\begin{array}{c}\text { Verbos Locativos } \\
\text { Preposicionales } \\
\text { VLP }\end{array}$ & $\cdot 35 \mathrm{LS} \cdot 35 \mathrm{LD} \cdot 37 \mathrm{LD} \cdot 38 \mathrm{LD} \cdot 38 \mathrm{LS}$ \\
$\cdot 38 \mathrm{LT} \cdot 38 \mathrm{R}$
\end{tabular} \\
$\begin{array}{c}\text { Verbos Locativos } \\
\text { Transitivos Directos } \\
\text { VLTD }\end{array}$ \\
\hline
\end{tabular}

Fuente: Rodrigues (2019, p. 130).

Aunque se haya hecho la clasificación basada en los verbos locativos descriptos en el LGLE, dejando de esa manera otras construcciones sin el debido análisis, creemos que tal sistematización pudo presentar las principales propiedades de las construcciones locativas de la lengua, siendo una importante contribución a los estudios descriptivos sintáctico-semánticos para contextos escolares.

\section{Consideraciones finales}

Este trabajo trata del fenómeno de las construcciones verbales locativas de la lengua española. A partir de la construcción del LGLE, realizado en una primera etapa de la investigación, se percibió la necesidad de proponer una sistematización de las construcciones a partir de una perspectiva más accesible al ambiente escolar, cuya terminología y consecuente definición pudiera ser utilizada con fines pedagógicos. De ese modo, los 318 verbos locativos del LGLE se redistribuyeron en dos grandes clases 
formales: verbos locativos preposicionales (VLP) y verbos locativos transitivos directos (VLTD), además de enfatizar sus principales propiedades semánticas, organizando los casos en verbos prototípicos, restrictivos y denominales -y la mención a las construcciones fóricas.

Las construcciones prototípicas se refieren a los verbos que tienen una mayor posibilidad y libertad de selección del argumental locativo. Los verbos restrictivos, en esta investigación, se limitaron a las construcciones que permiten la omisión de un argumento locativo (de origen o destino) y la selección de un nombre toponímico en la posición de argumental locativo. Ya el grupo de verbos denominales, además de apuntar las diferencias entre los verbos locativos y locatum, tan mencionados en la literatura lingüística, aún presenta la existencia de las construcciones denominales de lugar, de instrumento y de manera-posición.

Creemos que con esta investigación fue posible: (i) enfatizar la existencia de un argumental locativo, ampliando la función sintáctica de esos elementos, que generalmente, cuando en construcciones preposicionales, se limitan a ser analizados como circunstanciales; (ii) discutir sobre las particularidades generales del funcionamiento de las construcciones verbales locativas; y (iii) promover una propuesta de clasificación didáctica de los datos que puede ser utilizada en sala de clase para la enseñanza del fenómeno.

\section{Referencias}

BAPTISTA, J. ViPEr: uma base de dados de construções léxico-sintáticas de verbos do Português Europeu. In: XXVIII ENCONTRO NACIONAL DA ASSOCIAÇÃO PORTUGUESA DE LINGUÍSTICA. Textos Selecionados. Coimbra: APL, 2013, p. 111129.

BATISTA, Z. N. Estrutura linguística e informação: uma introdução à abordagem de Zellig S. Harris sobre os fenômenos da língua. Dissertação (Mestrado) - Faculdade de Letras, Universidade Federal de Goiás (UFG), Goiânia-GO, 2008. 
CAMPOS, H. Transitividad e intransitividad. In: Gramática descriptiva de la lengua española. Madrid: Espasa, 1999, p. 1519-1574.

CANÇADO, M., GODOY, L.; AMARAL, L. Catálogo de verbos do português brasileiro: classificação segundo a decomposição de predicados: verbos de mudança. Belo Horizonte: Editora UFMG, 2013.

CAVALCANTE, M. M. Facultatividade e omissão de complementos verbais. Revista de Letras, v. 19, Fortaleza, 1997, p. 13-24. DOI https://doi.org/10.11606/issn.25945963.lilit.1997.114257

CIFUENTES HONRUBIA, J. L. Sobre verbos locatum y de localización. In: Palabras, norma, discurso: en memoria de Fernando Lázaro Carreter. Salamanca: Ediciones Universidad de Salamanca, 2005, p. 333-346.

CORRÊA, R.; CANÇADO, M. Verbos de Trajetória do PB: uma descrição sintáticosemântica. Revista de Estudos da Linguagem, Belo Horizonte, 2006, p. 371-404. DOI https://doi.org/10.17851/2237-2083.14.2.371-404

ESPAÑOLA, Real Academia; ESPAÑOLA, Asociación de Academias de la Lengua. Nueva Gramática de la lengua española: manual. Madrid: Espasa, 2010.

GARCÍA-MIGUEL, J. M.; COSTAS, L.; MARTÍNEZ, S. Diátesis verbales y esquemas construccionales: Verbos, clases semánticas y esquemas sintáctico-semánticos en el proyecto ADESSE. VI CONGRESO INTERNACIONAL DE LINGÜÍSTICA HISPÁNICA. Anais. Leipzig, 2003, p. 7-12.

GARCÍA-MIGUEL, J. M. Los complementos locativos. In: Sintaxis histórica de la lengua española. México: Fondo de Cultura Económica, 2006.

GROSS, M. Méthodes en syntaxe. Paris: Hermann, 1975. DOI https://doi.org/10.3406/lgge.1981.1875

GROSS, M. Les bases empiriques de la notion de prédicat sémantique. Langages, 1981. p. 7-52.

GUILLET, A.; LECLÈRE, C. La structure des phrases simples en français: constructions transitives locatives. Genebra: Librairie Droz S.A, 1992.

LEVIN, B. English Verb Classes and Alternations: A Preliminary Investigation. Chicago: University of Chicago Press, 1993. 
MACEDO, M. E. Construções Transitivas Locativas. Centro de Linguística da Universidade de Lisboa. Lisboa, 1987.

MATERA, M.; MEDINA, R. Verbos Locatum y Verbos Locativos en español: Un acercamiento preliminar. Revista de Ciencias Humanas y Sociales, v. 21, n. 46, Maracaibo, 2005.

MIOTO, C.; SILVA, M. C. F.; VASCONCELLOS, R. E. Novo manual de sintaxe. Florianópolis: Insular, 3ํㅡㄹ edição, 2007.

NEVES, M. H. M. Gramática de usos do português. São Paulo: Editora da Universidade Estadual Paulista, 2000.

RODRIGUES, R. Análise contrastiva dos verbos locativos do português do Brasil e do português europeu. Dissertação (Mestrado em Linguística). Universidade Federal de São Carlos, São Carlos, 2016.

RODRIGUES, R. Contribuições para umA léxico-gramática das construções locativas do espanhol. Tese (Doutorado em Linguística). Universidade Federal de São Carlos, São Carlos, 2019.

ROJAS NIETO, C. Verbos Locativos en español: aproximación sintáctico-semántica. Instituto de investigaciones filológicas. México: Universidad Nacional de México, 1988. 